\title{
Low-Temperature Excess Heat Capacity of Potassium Germanate Glasses
}

\author{
Seiichi Mamiya ${ }^{1}$ \\ ${ }^{1}$ Graduate School of Pure and Applied Sciences, University of Tsukuba, Tsukuba, Ibaraki, Japan \\ Correspondence: Seiichi Mamiya, University of Tsukuba, 1-1-1 Tennodai, Tsukuba, Ibaraki 305-8573, Japan. \\ Tel: 81-29-853-6910. E-mail: mamiya@ims.tsukuba.ac.jp
}

Received: February 16, 2013

Accepted: April 2, $2013 \quad$ Online Published: April 15, 2013

doi:10.5539/mas.v7n5p22

URL: http://dx.doi.org/10.5539/mas.v7n5p22

\begin{abstract}
Low-temperature heat capacity of potassium germanate glasses $\left(x \mathrm{~K}_{2} \mathrm{O} \cdot(100-x) \mathrm{GeO}_{2} ; x=0.0,10.1,19.0,28.2\right.$, 39.0) ( $x$ indicates $\mathrm{K}_{2} \mathrm{O}$ mol\% content) has been measured in the temperature range from 2 to $50 \mathrm{~K}$ with $\mathrm{K}_{2} \mathrm{O}$ content. From a result of the heat capacity $C_{p}$, it has been found that an excess heat capacity is not caused by a regular thermal motion but an interaction. In addition, it has also been found that a relationship between a maximum of reduced excess heat capacity $C_{p} T^{-3}{ }_{\max }$ and elastic modulus is dual. Moreover, a 'hole' model of liquid theory was applied to explain the formation of resonant mechanism. This model leads us to an idea that the excess heat capacity is described by degree of freedom of reallocated-and-isolated-structural units. Consequently, we conclude that the excess heat capacity is caused by the reallocated-main-network structure containing holes resonant with the reallocated-and-isolated-microstructural units.
\end{abstract}

Keywords: low-temperature heat capacity, potassium germanate glasses, excess heat capacity, interaction, dual, 'hole' model of liquid theory, degree of freedom, reallocated-and-isolated-structural units

\section{Introduction}

\subsection{Purpose of Reseach}

The purpose of reseach is to measure the heat capacities $C_{p}$ of potassium germanate glasses in the range of temperature from 2 to $50 \mathrm{~K}$ with $\mathrm{K}_{2} \mathrm{O}$ content and to clarify an origin of the excess heat capacity compared with the Debye model from a viewpoint of the microstructure.

\subsection{Germanate Anomaly}

The glass has been used in a human life from an ancient time after ceramics and studied invariably then applied to a wide variety of fields for new products. Germanate glasses we study are used as a core part of optical fiber and an infrared emitting window. Alkali-oxide germanate glass exhibits 'germanate anomaly' (Henderson, 2007). Germanate anomaly means when alkali-oxide such as $\mathrm{Li}_{2} \mathrm{O}, \mathrm{Na}_{2} \mathrm{O}$ or $\mathrm{K}_{2} \mathrm{O}$ is added to germania $\left(\mathrm{GeO}_{2}\right)$, a physical property of the resulting glass exhibits a maximum or a minimum at some addition of alkali-oxide content, for instance, a density of potassium germanate glass shows a maximum at about $10 \mathrm{~mol} \% \mathrm{~K}_{2} \mathrm{O}$ content. On the other hand, when alkali-oxide is added to silica $\left(\mathrm{SiO}_{2}\right)$, a physical property of the resulting glass shows neither a maximum nor a minimum. This anomaly is showed in many physical properties e.g. density, refractive index, glass transition temperature, viscosity, micro-hardness, internal friction, acoustic velocity and elastic moduli. The germanate anomaly has been extensively researched (Henderson, 2007; Yiannopoulos, Kamitsos, \& Jain, 1997; Kamitsos, Yiannopoulos, Karakassides, Chryssikos, \& Jain, 1996; Yiannopoulos, Varsamis, \& Kamitsos, 2001; Yiannopoulos, Varsamis, \& Kamitsos, 2002; Henderson \& Fleet, 1991; Wang \& Henderson, 2004; Soltay \& Henderson, 2005; Hannon, Martino, Santos, \& Almeida, 2007; Kiczenski, Hammarsten, Wilkerson, Affatigato, \& Feller, 2000), especially a lot of studies by Kamitsos et al. (Yiannopoulos et al., 1997; Kamitsos et al.,1996; Yiannopoulos et al., 2001; Yiannopoulos et al., 2002) and Henderson et al. (Henderson, 2007; Henderson \& Fleet, 1991; Wang \& Henderson, 2004; Soltay \& Henderson, 2005).

\subsection{Historical Background}

We follow the route of the research on low-temperature thermal properties for the past fifty years or so. First, in 1971, Zeller and Pohl (1971) have revealed universal properties of amorphous solids including glasses in low-temperature. They measured the specific heat and thermal conductivity of vitreous silicate- and 
germanate-system and selenium in the temperature range from 0.05 to $100 \mathrm{~K}$. They found that the low-temperature thermal properties of amorphous solid are different from those of crystalline solid. It was found that the thermal conductivity varies as $T^{1.8}$ below $T=1 \mathrm{~K}$ and the specific heat varies as $A T+B T^{3}$ between 0.1 and $1 \mathrm{~K}$ ( $A$ and $B$ are constants). In addition, the excess specific heat and the plateau of thermal conductivity around $10 \mathrm{~K}$ were also discussed. The following year 1972, Anderson, Halperin and Varma (1972) and Phillips (1972) proposed a tunneling model respectively, which explains the anomaly of the specific heat and thermal conductivity in amorphous solid below 1 K. From 1980 to 2000, the excess heat capacity and plateau of thermal conductivity at about $10 \mathrm{~K}$ were explained using the extension of the tunneling model in combination with Rayleigh scattering, sound waves and soft localized vibrations by Yu and Freeman (1987), Buchenau, Galperin, Gurevich, Parshin, Ramos and Schober (1992) and Gil, Ramos, Bringer and Buchenau (1993) respectively. Since 2000, the excess heat capacity at about $T=10 \mathrm{~K}$ has been discussed separately from the thermal property below 1 $\mathrm{K}$. For example, in 2003 , the heat capacity of $\mathrm{B}_{2} \mathrm{O}_{3}$ and $\mathrm{GeO}_{2}$ glasses were measured from less than 10 to $350 \mathrm{~K}$ and at $0 \mathrm{~K}$ their excess entropies were calculated by Richet, Ligny and Westrum (2003). In addition, the relationship between the importance of (calorimetric) Boson peak and glass transition temperature was mentioned. In 2009, the vibrational density of states was represented from inversion of low-temperature heat capacities of vitreous $\mathrm{SiO}_{2}$ and a series of $\mathrm{Li}, \mathrm{Na}$ and $\mathrm{K}$ silicate glasses from 10 to $300 \mathrm{~K}$ by Richet (2009). The relationship between the vibrational density of states and the heat capacity of glasses was discussed. In 2010, the effects of the substitution of nitrogen for oxygen on the heat capacity and vibrational entropy of several yttrium aluminosilicate glasses with $\mathrm{Si}_{3} \mathrm{~N}_{4}$ contents have been investigated by Richet, Rouxel, Kawaji and Nicolas (2010). Of course, the vibrational density of states was also calculated and compared with heat capacity. Moreover, the relationship between (calorimetric) Boson peak and elastic modulus was analyzed. As mentioned above, a lot of papers have been dedicated to a problem about the energy in glasses but few papers have been dedicated to a problem about the microsturucture in glasses. Therefore, there is room for an intensive study of the problem about microstructure and we may acquire some useful information on the excess heat capacity.

\section{Method}

We study the relationship between two germanate anomalies on the basis of the microstructure. The microstructure of potassium germanate glasses has been obtained from our Raman scattering measurement (Mamiya, Matsuda, Fukawa, Kawashima, \& Kojima, 2009). Two germanate anomalies mean they have a same $\mathrm{K}_{2} \mathrm{O}$ content at which each anomaly shows a maximum or a minimum of its physical property. We perform an experiment according to the following procedure.

1) Sample preparation

2) Low-temperature heat capacity measurement

3) To find the germanate anomaly about the excess heat capacity

4) To find the counterpart of the germanate anomaly about the excess heat capacity

5) To discuss and investigate the relationship between the two germanate anomalies on the basis of the microstructure

6) To clarify the origin of the excess heat capacity in the potassium germanate glass

\subsection{Sample Preparation}

Four glass samples were prepared in the series of $x \mathrm{~K}_{2} \mathrm{O} \cdot(100-x) \mathrm{GeO}_{2} ; x=10.1,19.0,28.2,39.0$. All the glasses were synthesized by the solution method (Kodama, Matsushita, \& Kojima, 1995; Matsuda, Fukawa, Ike, Kodama, \& Kojima, 2008). The advantage of this method is that the starting materials are initially made to react in an aqueous solution to achieve homogeneity. Analytical reagent-grade $\mathrm{KOH} \cdot \mathrm{H}_{2} \mathrm{O}$ and $\mathrm{GeO}_{2}$ were used as the starting materials without further purification. The starting materials were made to react by adding distilled pure water in a Teflon beaker. The beaker containing the solution was then placed in a drying oven at $140{ }^{\circ} \mathrm{C}$ for 7 days. After the complete evaporation of water, a chemically synthesized powder was obtained. This powder was melted in a Pt crucible for 1.5 hours at about 950 to $1100{ }^{\circ} \mathrm{C}$ depending on the content. The homogenized bubble-free melts were cast in a graphite mold for bulk glasses and splat-quenched. For $x=0.0$, the germania $\left(\mathrm{GeO}_{2}\right)$ glass sample was prepared by $\mathrm{M}$. Kodama. The method of $\mathrm{GeO}_{2}$ glass preparation has been described by Zeller and Pohl (1971). The content of each glass was chemically analyzed (Kodama, Iizuka, Miyashita, Nagai, Clarida, Feller, \& Affatigato, 2003). The analyzed value was used in this study.

\subsubsection{Sample Size}

The five splat-quenched glasses were ground to shape a block of about $2 \times 2 \times 1.5$ (thickness) $\mathrm{mm}^{3}$ for the 
low-temperature heat capacity measurement and preserved in a desiccator to keep free from moisture.

\subsection{Low-Temperature Heat Capacity Measurement}

The heat capacity of potassium germanate glasses was measured in the range of temperature from 2 to $50 \mathrm{~K}$ with $\mathrm{K}_{2} \mathrm{O}$ content using Physical Property Measurement System (PPMS) of Quantum Design (c) at the Cryonics Div., Research Facility Center of Tsukuba University. The heat capacity was measured by the thermal relaxation method and calculated by subtracting an addenda measurement from the total capacity. The addenda measurement means the measurement of the heat capacity of the grease and the platform (Richet et al., 2010).

\section{Results}

Figure 1 shows the heat capacity $C_{p}$ of the potassium germanate glasses with $\mathrm{K}_{2} \mathrm{O}$ content between 2 and $50 \mathrm{~K}$. The heat capacities were converted from a mol to a $\mathrm{g}$ atom bases to make consistent comparisons. The $C_{p}$ of germania $\left(\mathrm{GeO}_{2}\right)$ glass is good agreement with that of $\mathrm{GeO}_{2}$ glass measured by P. Richet et al. (2003).

\subsection{Reduced Excess Heat Capacity $C_{p} T^{-3}$}

Figure 2 shows a reduced excess heat capacity $C_{p} T^{-3}$ compared with Debye $T^{3}$ laws. The $C_{p} T^{-3}$ of germania $\left(\mathrm{GeO}_{2}\right)$ glass is also good agreement with that of $\mathrm{GeO}_{2}$ glass measured by P. Richet et al. (2003). Their $C_{p} T^{-3}$ graph of $\mathrm{GeO}_{2}$ glass is described using mol bases. In Figure 2, every $C_{p} T^{-3}$ exhibits a maximum around $10 \mathrm{~K}$. The $C_{p} T^{-3}$ of all glasses increases with increasing $\mathrm{K}_{2} \mathrm{O}$ content around $T=50 \mathrm{~K}$. However, the $C_{p} T^{-3}$ of $\mathrm{GeO}_{2}$ glass increases and crosses those of the other three $\mathrm{K}_{2} \mathrm{O}$ content glasses with decreasing temperature $T$. This behavior is very similar to the silica $\left(\mathrm{SiO}_{2}\right)$ glass in sodium silicate system (Richet, 2009).

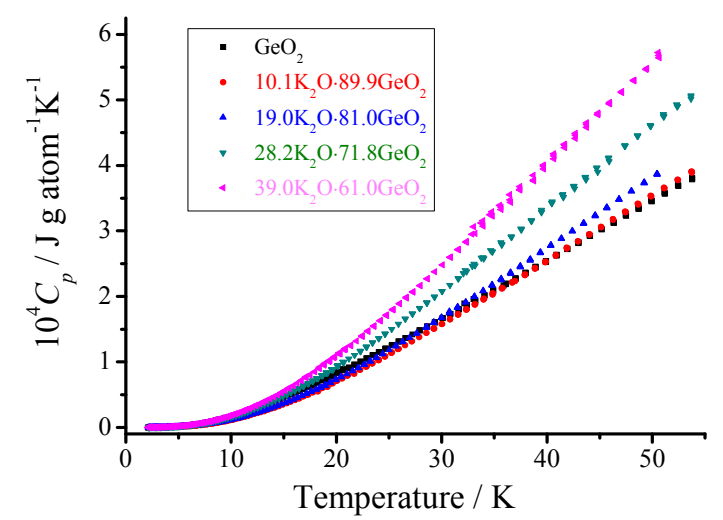

Figure 1 . The temperature dependence of heat capacity $C_{p}$ of potassium germanate glasses with $\mathrm{K}_{2} \mathrm{O}$ content $(x=0.0,10.1,19.0,28.2,39.0)$

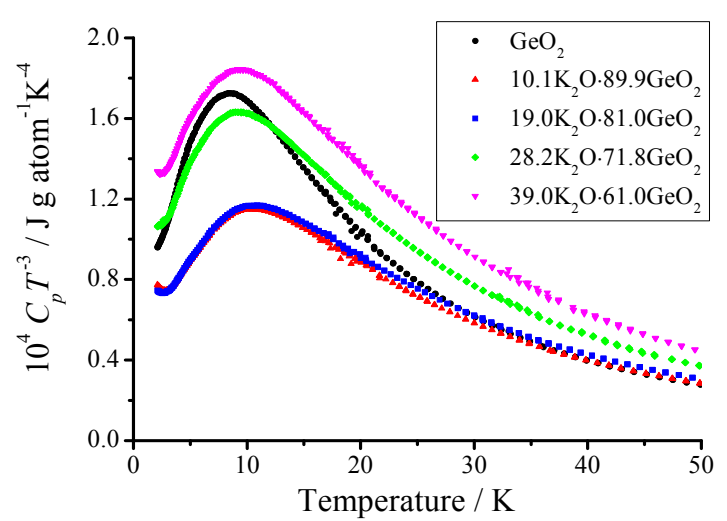

Figure 2. The temperature dependence of reduced excess heat capcity of potassium germanate glasses with $\mathrm{K}_{2} \mathrm{O}$ content $(x=0.0,10.1,19.0,28.2,39.0)$ 


\subsection{Maximum of Reduced Excess Heat Capacity $C_{p} T^{-3}{ }_{\max }$}

Figure 3 shows the maximum of reduced excess heat capacity $C_{p} T^{-3}{ }_{\max }$ with $\mathrm{K}_{2} \mathrm{O}$ content. The $C_{p} T^{-3}{ }_{\text {max }}$ indicates the maximum of the $C_{p} T^{-3}$. As the $C_{p} T^{-3}$ max shows a minimum for $x=15$, this is the germanate anomaly about the excess heat capacity.

\subsection{Counterpart of Germanate Anomaly about Maximum of Reduced Excess Heat Capacity $C_{p} T^{-3}{ }_{\max }$}

We determine the counterpart of the germanate anomaly about the maximum of reduced excess heat capacity $C_{p} T^{-3}$ max. Figure 4 shows the elastic moduli we measured (Mamiya, Matsuda, Kaneda, Kawashima, \& Kojima, 2010). The elastic modulus exhibits a maximum for $x=15$. Therefore, the elastic modulus is the counterpart of the germanate anomaly about the maximum of reduced excess heat capacity. Compared with Figure 3, the behavior of the elastic modulus is opposite to that of the maximum of reduced excess heat capacity $C_{p} T^{-3}{ }_{\max }$. We will mention about the resonance and a 'hole' model of liquid theory as the feedback from the experimental results in the next section.

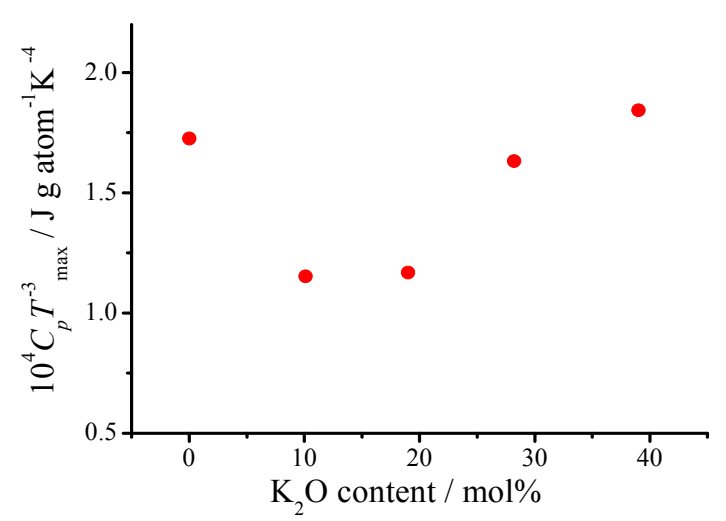

Figure 3. The content dependence of maximum of reduced excess heat capacity $C_{p} T^{-3}$ max of potassium germanate glasses

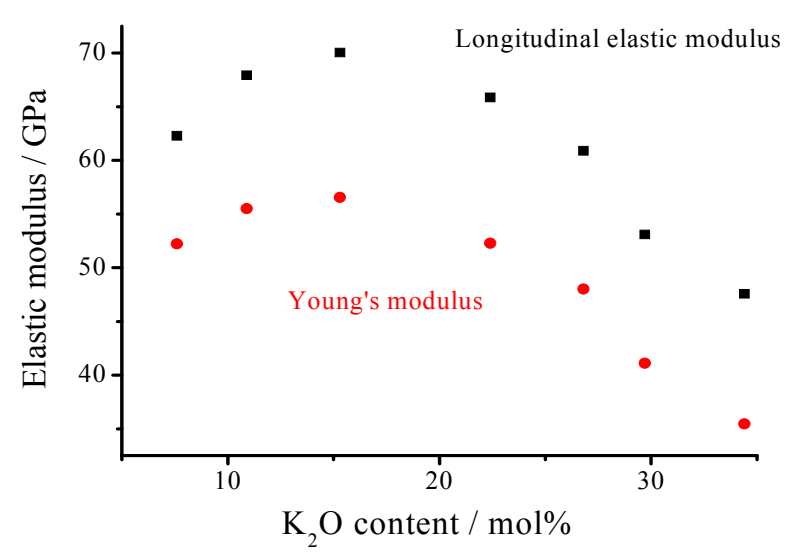

Figure 4. The content dependence of elastic moluli of potassium germanate glasses

\section{Discussion}

\subsection{Resonance}

In Figure 2, every excess heat capacity $C_{p} T^{-3}$ reaches the peak around $10 \mathrm{~K}$. This phenomenon seems to be a resonance (Halliday, Resnick, \& Walker, 2001). Especially, the behavior of the $\mathrm{GeO}_{2}$ glass is interesting. This means the $\mathrm{GeO}_{2}$ glass has the microstructure which makes resonant intensity larger than the other three $\mathrm{K}_{2} \mathrm{O}$ content glasses. And there are two indispensable factors in the resonance. They are a forced (driven) oscillator and a free oscillator. The forced oscillator is considered as the regular thermal motion. Because Chumakov et al. (2011) have concluded that the density of states (DOS) shows that the glass and the relevant crystal have the 
same number of states and suggested the DOS of the glass does not contain additional modes in the low-energy region. And the free oscillator is considered as the asymmetric stretching mode of $\mathrm{Ge}(4)-\mathrm{O}-\mathrm{Ge}(4)$. $\mathrm{Ge}(4)$ indicates a 4 coordinate $\mathrm{Ge}$ atom. Because the asymmetric stretching mode of $\mathrm{Ge}(4)-\mathrm{O}-\mathrm{Ge}(4)$ causes the free oscillation, for instance, it makes the 6-membered ring of $\mathrm{GeO}_{4}$ tetrahedra swing around the center of the ring. We next introduce a 'hole' model of lquid theory (Temperley \& Trevena, 1978) to explain the mechanism that produces the forced oscillator and the free oscillator in the glass.

\subsection{The 'Hole' Model of Liquid Theory}

When a solid is melted into a liquid, the volume of the resulting liquid generally increases by $5 \sim 15 \%$. From $\mathrm{X}$-ray and neutron diffraction analysis, the original long-range order is broken at the melting point, however, a good deal of local or the short-range order over melting point still remains in a liquid. The increase in volume on melting is considered not the increase in the interatomic distance but rather the decrease in the coordination number. A structural unit in the melt hopping out of the main network structure by thermal energy makes a hole in the main network structure and the isolated structural unit away from the main network structure simultaneously. As the melt is rapid-quenched, consequently, the main network structure containing holes is reallocated to a metastable state and the isolated structural units are also reallocated to metastable states such as the 6-membered ring of $\mathrm{GeO}_{4}$ tetrahedra or the 3-membered ring of $\mathrm{GeO}_{4}$ tetrahedra (Mamiya et al., 2009). From here, the former stable state and the latter stable states are written the reallocated-main-network structure and the reallocated-and-isolated-microstructural units respectively. Therefore, the forced oscillator and the free oscillator are assigned to the reallocated-main-network structure containing holes and the reallocated-and-isolated-structural unit respectively. The physical property of glass is characterized by the reallocated-and-isolated-microstructural units with increasing $\mathrm{K}_{2} \mathrm{O}$ content. Because that as the reallocated-and-isolated-microstructural unit is isolated and outside the reallocated-main-network structure containing holes, $\mathrm{K}_{2} \mathrm{O}$ affects the reallocated-and-isolated-microstructural unit more effectively than the reallocated-main-network structure containing holes. That is to say the physical property, for instance the excess heat capacity or the elastic modulus, is characterized by the reallocated-and-isolated-microstructural units with $\mathrm{K}_{2} \mathrm{O}$ content. The relationship between the reduced excess heat capcity and the elastic modulus is dual, because the measurement of excess heat capacity is equivalent to the measurement of the degree of freedom in the reallocated-and-isolated microstructure and the measurement of elastic modulus is equivalent to the measurement of the degree of constraint in the reallocated-and-isolated microstructure. That is as the relationship between degree of freedom and degree of constraint is dual, the above relationship is true.

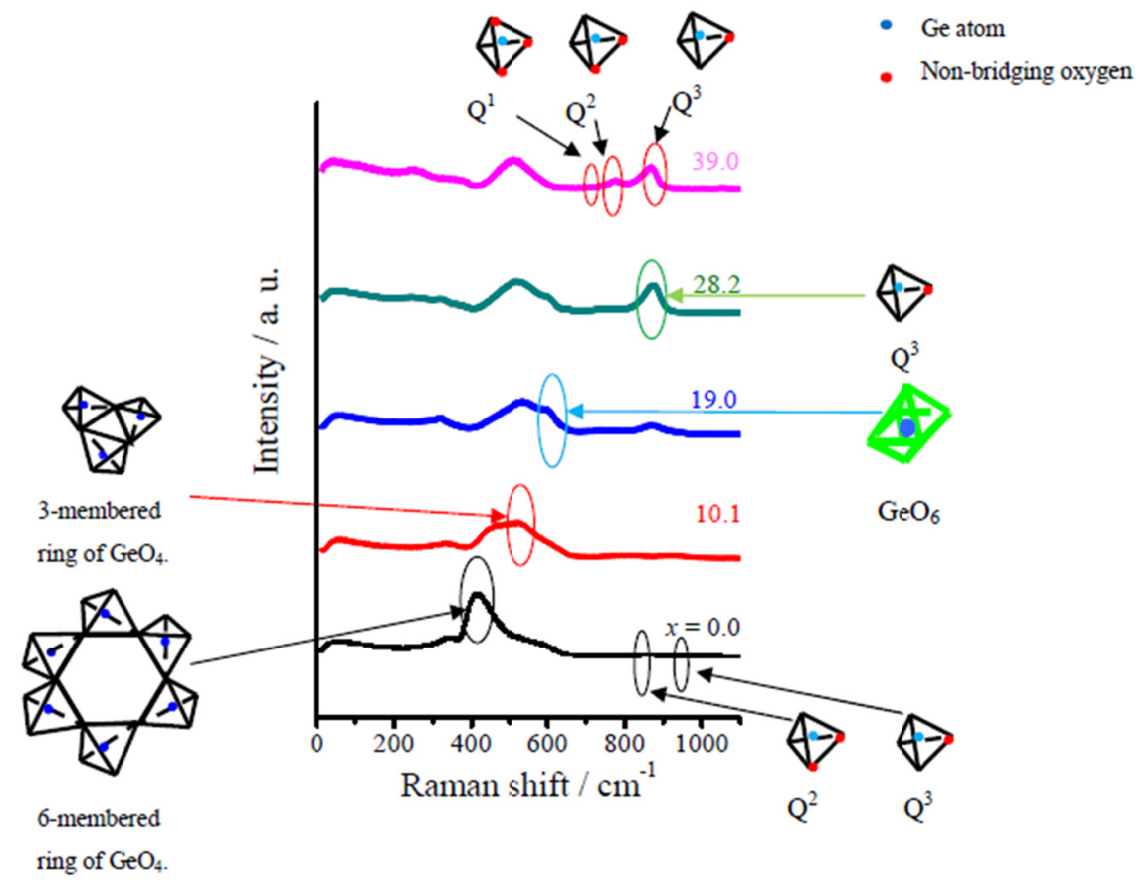

Figure 5. The content dependence of Raman spectra and microstructure units of potassium germanate glasses $(x=0.0,10.0,19.0,28.2,39.0)$ 


\subsection{Relationship between Two Properties on the Basis of Microstructure}

We discuss the relationship between the elastic modulus and the maximum of reduced excess heat capacity $C_{p} T^{-3}{ }_{\text {max }}$ on the basis of the microstructure from our Raman scattering measurement (Figure 5). For $0 \leq x \leq 20$, the elastic modulus is described by superposition of two factors. The one factor is the number of 3-membered rings of $\mathrm{GeO}_{4}$ tetrahedra. Because 6-membered ring of $\mathrm{GeO}_{4}$ tetrahedra (for $x=0.0$, Raman band at $420 \mathrm{~cm}^{-1}$ ) is broken down to two pieces of 3-membered rings of $\mathrm{GeO}_{4}$ tetrahedra by $\mathrm{K}_{2} \mathrm{O}$ and the structure of 3-membered ring of $\mathrm{GeO}_{4}$ tetrahedra is denser and harder than that of 6-membered ring of $\mathrm{GeO}_{4}$ tetrahedra. The other factor is the number of $\mathrm{GeO}_{6}$ octahedra. Because m-membered chain of $\mathrm{GeO}_{4}$ tetrahedra containing $\mathrm{Q}^{3}$ or $\mathrm{Q}^{2}$ is changed into $\mathrm{m}$-membered chain of $\mathrm{GeO}_{4}$ and $\mathrm{GeO}_{6}$ octahedra by $\mathrm{K}_{2} \mathrm{O}$, the structure of $\mathrm{GeO}_{6}$ octahedron is harder and more stable than that of $\mathrm{Q}^{3}$ or $\mathrm{Q}^{2}$. There are a few m-membered chains of $\mathrm{GeO}_{4}$ tetrahedra containing $\mathrm{Q}^{3}$ or $\mathrm{Q}^{2}$ in this $\mathrm{K}_{2} \mathrm{O}$ content (The number $\mathrm{m}$ is more than $4, \mathrm{Q}^{\mathrm{n}}$ species indicate the $\mathrm{GeO}_{4}$ tetrahedron with 4-n non-bridging oxygens and $\mathrm{Q}^{3}$ and $\mathrm{Q}^{2}$ are in Raman bands at 956 and $858 \mathrm{~cm}^{-1}$ for $x=0.0$ respectively). $\mathrm{Q}^{3}$ and $\mathrm{Q}^{2}$ in the m-membered chain of $\mathrm{GeO}_{4}$ tetrahedra containing $\mathrm{Q}^{3}$ or $\mathrm{Q}^{2}$ is not broken down by $\mathrm{K}_{2} \mathrm{O}$ but reallocated to a metastable state by rapid-quenching. For $20<x<30$, as 3-memebered rings of $\mathrm{GeO}_{4}$ tetrahedra in the reallocated-and-isolated microstructure disappear, $\mathrm{K}_{2} \mathrm{O}$ breaks down other isolated structural unit, for example, 3-membered chain of $\mathrm{GeO}_{4}$ tetrahedra and $\mathrm{GeO}_{6}$ octahedra. For $30 \leq x \leq 40$, the reallocated-main-network structure containing holes is also broken down to 3-membered chain of $\mathrm{GeO}_{4}$ tetrahedra containing $\mathrm{Q}^{3}$ or $\mathrm{Q}^{2}$ by $\mathrm{K}_{2} \mathrm{O}$. However, as 3-membered chain of $\mathrm{GeO}_{4}$ tetrahedra containing $\mathrm{Q}^{3}$ or $\mathrm{Q}^{2}$ is included in the reallocated-and-isolated-microstructural units, the elastic modulus is also determined by the reallocated-and-isolated-microstructural units. Figure 6 shows the content dependence of integrated intensity of vibrational band centered at $520 \mathrm{~cm}^{-1}$ ascribed to 3-membered ring of $\mathrm{GeO}_{4}$ tetrahedra (Mamiya et al., 2009). For $x=0.0$, there are 3-membered rings of $\mathrm{GeO}_{4}$ tetrahedra in the reallocated-main-network structure containing holes and the vibrational band at $420 \mathrm{~cm}^{-1}$ drastically decreases with $\mathrm{K}_{2} \mathrm{O}$ content, whereas the vibrational band at 520 $\mathrm{cm}^{-1}$ drastically increases with $\mathrm{K}_{2} \mathrm{O}$ content. This means 6-membered rings of $\mathrm{GeO}_{4}$ tetrahedra are converted to 3-membered rings of $\mathrm{GeO}_{4}$ tetrahedra with $\mathrm{K}_{2} \mathrm{O}$ content. The e-membered rings of $\mathrm{GeO}_{4}$ tetrahedra reach the maximum for about $x=10$ and drastically decrease, and then down to the initial value (for germania glass) for $x=20$, almost remain unchanged for $20<x<30$, and afterward decrease again. Figure 7 exhibits the content dependence of $\mathrm{Ge}$ atom (Yiannopoulos et al., 1997). For $x=0.0$, every Ge atom is 4 coordination. When $\mathrm{K}_{2} \mathrm{O}$ is added to germania $\left(\mathrm{GeO}_{2}\right)$ glass, 6 coordinated Ge atom increases and reaches the maximum for about $x=20$ and then decreases down to the initial state for $x=45$. This also indicates the number of $\mathrm{GeO}_{6}$ octahedron. We investigate the change of microstructure with respect to the elastic modulus. For the purpose of description and discussion, it is useful to divide the range of $\mathrm{K}_{2} \mathrm{O}$ content into 4 regions, the low- $\mathrm{K}_{2} \mathrm{O}$-content region from 0 to $10 \mathrm{~mol} \%$, the middle- $\mathrm{K}_{2} \mathrm{O}$-content region from 10 to $20 \mathrm{~mol} \%$, the high- $\mathrm{K}_{2} \mathrm{O}$-content region from 20 to $30 \mathrm{~mol} \%$, the higher- $\mathrm{K}_{2} \mathrm{O}$-content region from 30 to $40 \mathrm{~mol} \%$.

\subsubsection{The Low- $\mathrm{K}_{2} \mathrm{O}$-Content Region (0 to $10 \mathrm{~mol} \%$ )}

For $x=0.0$, there are a number of 6-membered rings of $\mathrm{GeO}_{4}$ tetrahedra and a few m-membered chains of $\mathrm{GeO}_{4}$ tetrahedra containing $\mathrm{Q}^{3}$ or $\mathrm{Q}^{2}$. When $\mathrm{K}_{2} \mathrm{O}$ is added to the $\mathrm{GeO}_{2}$ glass, 6-membered rings of $\mathrm{GeO}_{4}$ tetrahedra are changed into 3-membered rings of $\mathrm{GeO}_{4}$ tetrahedra and $\mathrm{m}$-membered chains of $\mathrm{GeO}_{4}$ tetrahedra containing $\mathrm{Q}^{3}$ or $\mathrm{Q}^{2}$ is converted into m-membered chains of $\mathrm{GeO}_{4}$ tetrahedra and $\mathrm{GeO}_{6}$ octahedron. Because the $\mathrm{K}_{2} \mathrm{O}$ breaks down 6-membered ring of $\mathrm{GeO}_{4}$ tetrahedra into two pieces of 3-membered rings of $\mathrm{GeO}_{4}$ tetrahedra and it also converts $\mathrm{Q}^{3}$ or $\mathrm{Q}^{2}$ to $\mathrm{GeO}_{6}$ octahedron. The number of 3-membered rings of $\mathrm{GeO}_{4}$ tetrahedra increases and the number of $\mathrm{GeO}_{6}$ also increases. As the superposition of the two factors increases, the elastic modulus also increases. When we turn our attention to the vibrational intensity of the microstructure, the torque of 3-membered ring of $\mathrm{GeO}_{4}$ tetrahedra is a quarter of that of 6-membered ring of $\mathrm{GeO}_{4}$ tetrahedra, however, the number of 3-membered rings of $\mathrm{GeO}_{4}$ tetrahedra becomes two times of that of 6-membered rings of $\mathrm{GeO}_{4}$ tetrahedra. The torque means the moment of rotation around center of ring that is caused by asymmetric vibrational mode of $\mathrm{Ge}(4)-\mathrm{O}-\mathrm{Ge}(4)$. As the vibrational intensity of 3-membered rings of $\mathrm{GeO}_{4}$ tetrahedra becomes a half of that of 6 -membered rings of $\mathrm{GeO}_{4}$ tetrahedra, the vibrational intensity drastically decreases. That is when the 6-membered ring of $\mathrm{GeO}_{4}$ tetrahedra is changed into the two pieces of 3-membered rings of $\mathrm{GeO}_{4}$ tetrahedra, its vibrational intensity decreases down to a half. In the case of m-membered chains of $\mathrm{GeO}_{4}$ tetrahedra containing $\mathrm{Q}^{3}$ or $\mathrm{Q}^{2}, \mathrm{Q}^{3}$ or $\mathrm{Q}^{2}$ has a large vibrational intensity because they contain non-bridging oxygens. Besides, $\mathrm{GeO}_{6}$ octahedron has a small vibrational intensity because it is a stable state and a strong bonding of octahedron. That is when m-membered chain of $\mathrm{GeO}_{4}$ tetrahedra containing $\mathrm{Q}^{3}$ or $\mathrm{Q}^{2}$ are conveted into m-membered chain of $\mathrm{GeO}_{4}$ tetrahedra and $\mathrm{GeO}_{6}$, its vibrational intensity decreases. As the superposition of two factors drastically decreases, the vibrational intensity also drastically decreases. 


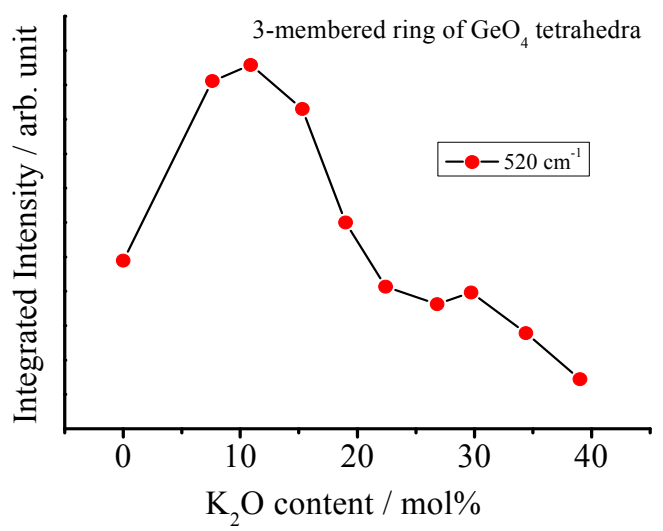

Figure 6. The content dependence of integrated intensity of vibrational band centered at $520 \mathrm{~cm}^{-1}$

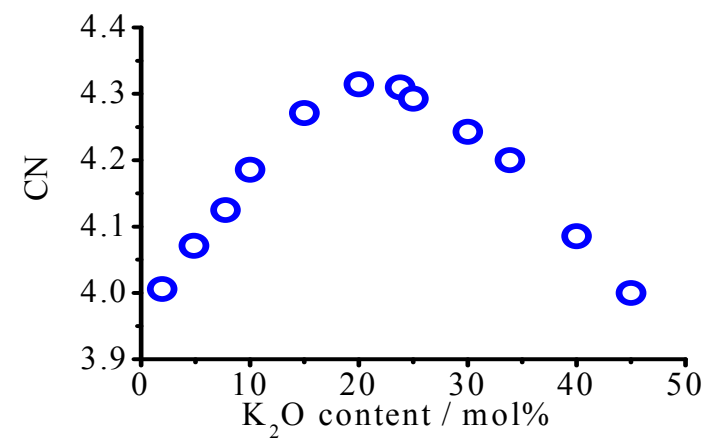

Figure 7. The content dependence of average coordination number of $\mathrm{Ge}$ atoms ( $\mathrm{CN}$ indicates average coordination number)

\subsubsection{The Middle- $\mathrm{K}_{2} \mathrm{O}$-Content Region (10 to $20 \mathrm{~mol} \%$ )}

For $x=10.0$, 6-membered rings of $\mathrm{GeO}_{4}$ tetrahedra almost disappear and the number of 3-membered rings of $\mathrm{GeO}_{4}$ tetrahedra becomes the maximum. For $10.0<x<15.0$, the number of 3-membered rings of $\mathrm{GeO}_{4}$ tetrahedra decreases gradually and the number of $\mathrm{GeO}_{6}$ increases drastically. As the superposition of the two factors still increases, the elastic modulus also increases. When we turn our attention to the vibrational intensity of the microstructure, 3-membered rings of $\mathrm{GeO}_{4}$ tetrahedra are gradually broken down to 3-membered chains of $\mathrm{GeO}_{4}$ containing $\mathrm{Q}^{3}$ by $\mathrm{K}_{2} \mathrm{O}$. As chain and $\mathrm{Q}^{3}$ have a free end and non-bridging oxygen respectively, the vibrational intensity of 3-membered chain of $\mathrm{GeO}_{4}$ tetrahedra containing $\mathrm{Q}^{3}$ is larger than that of 3-membered ring of $\mathrm{GeO}_{4}$ tetrahedra. When m-membered chains of $\mathrm{GeO}_{4}$ tetrahedra containing $\mathrm{Q}^{3}$ or $\mathrm{Q}^{2}$ are drastically converted into m-membered of chains of $\mathrm{GeO}_{4}$ tetrahedra and $\mathrm{GeO}_{6}$ octahedra by $\mathrm{K}_{2} \mathrm{O}$, the vibrational intensity decreases rapidly. As the superposition of two factors slightly decreases, the vibrational intensity of the two factors slightly decreases. For $x=15$, the elastic modulus is the maximum. On the contrary, the vibrational intensity is the minimum. For $15.0<x<20.0$, 3-membered rings of $\mathrm{GeO}_{4}$ tetrahedra keep decreasing drastically and $\mathrm{GeO}_{6}$ octahedra gradually increase. As the superposition of the two factors slightly decreases, the elastic modulus slightly decreases. When we turn our attention to the vibrational intensity of the microstructure, 3-membered rings of $\mathrm{GeO}_{4}$ tetrahedra keep being broken down to the 3-membered chains of $\mathrm{GeO}_{4}$ tetrahedra containing $\mathrm{Q}^{3}$ by $\mathrm{K}_{2} \mathrm{O}$. The vibrational intensity of 3-membered ring of $\mathrm{GeO}_{4}$ tetrahedra drastically increases, because of increasing species of $\mathrm{Q}^{3}$. The $\mathrm{m}$-membered chains of $\mathrm{GeO}_{4}$ tetrahedra containing $\mathrm{Q}^{3}$ or $\mathrm{Q}^{2}$ are slightly converted into $\mathrm{GeO}_{6}$ octahedra, because the two bands in Raman spectra are very weak and Figure 7 shows the slope of the average coordination number of $\mathrm{Ge}$ atom $(\mathrm{CN})$ is low. The vibrational intensity of $\mathrm{GeO}_{6}$ octahedra slightly decreases. As the superposition of the two factors gradually increases, the vibrational intensity gradually increases. 


\subsubsection{The High- $\mathrm{K}_{2} \mathrm{O}$-Content Region (20 to $30 \mathrm{~mol} \%$ )}

The number of 3-membered rings of $\mathrm{GeO}_{4}$ tetrahedra almost remains unchanged. Because 3-membered ring of $\mathrm{GeO}_{4}$ tetrahedra in the isolated structure is all broken down by $\mathrm{K}_{2} \mathrm{O}$. We must consider 3-membered chain of $\mathrm{GeO}_{4}$ tetrahedra containing $\mathrm{Q}^{3}$ which 3-membered rings of $\mathrm{GeO}_{4}$ tetrahedra were broken down to. As 3-membered chains of $\mathrm{GeO}_{4}$ tetrahedra containing $\mathrm{Q}^{3}$ are further broken down into 3-membered chaings of $\mathrm{GeO}_{4}$ tetrahedra containing $\mathrm{Q}^{3}$ and $\mathrm{Q}^{2}$, the elastic modulus drastically decreases. The number of the $\mathrm{GeO}_{6}$ octahedra reaches the maximum for $x=20$ and then decreases. $\mathrm{As}_{\mathrm{GeO}_{6}}$ octahedron is broken down to $\mathrm{Q}^{3}$ by the $\mathrm{K}_{2} \mathrm{O}$, the elastic modulus of $\mathrm{GeO}_{6}$ octahedron begins to decrease. Therefore, the superposition of the two factors continues decreasing drastically and the elastic modulus of the glass continues decreasing drastically. When we turn our attention to the vibrational intensity, the number of 3-membered rings of $\mathrm{GeO}_{4}$ tetrahedra almost remains intact. As the m-membered chains of $\mathrm{GeO}_{4}$ tetrahedra and $\mathrm{GeO}_{6}$ octahedra are converted into the m-membered chains of $\mathrm{GeO}_{4}$ tetrahedra containing $\mathrm{Q}^{3}$, the vibrational intensity drastically increases. As the superposition of the two factors drastically increases, the vibrational intensity of glass drastically increases.

\subsubsection{The Higher- $\mathrm{K}_{2} \mathrm{O}$-Content Region (30 to $40 \mathrm{~mol} \%$ )}

As 3-membered chains of $\mathrm{GeO}_{4}$ tetrahedra containing $\mathrm{Q}^{3}$ and $\mathrm{Q}^{2}$ are broken into 3-membered chains of $\mathrm{GeO}_{4}$ tetrahedra containing $\mathrm{Q}^{3}, \mathrm{Q}^{2}$ and $\mathrm{Q}^{1}$, the elastic modulus further decreases. The $\mathrm{m}$-membered chains of $\mathrm{GeO}_{4}$ tetraheda containing $\mathrm{Q}^{3}$ are broken into the chains of $\mathrm{GeO}_{4}$ tetrahedra containing $\mathrm{Q}^{3}$ and $\mathrm{Q}^{2}$. When 3-membered rings of $\mathrm{GeO}_{4}$ tetrahedra as the reallocated-and-isolated-structural unit disappear, 3-membered rings of $\mathrm{GeO}_{4}$ tetrahedra in the reallocated-main-network structure are broken into the 3-membered chains of $\mathrm{GeO}_{4}$ tetrahedra containing $\mathrm{Q}^{3}$ by $\mathrm{K}_{2} \mathrm{O}$. Raman bands at 866,774 and $710 \mathrm{~cm}^{-1}$ indicate $\mathrm{Q}^{3}, \mathrm{Q}^{2}$ and $\mathrm{Q}^{1}$ (for $x=39.0$ ) respectively. These bands grow drastically. All the structures are broken down into the structures containing more $Q^{3}, Q^{2}$ and $\mathrm{Q}^{1}$. Therefore, the elastic modulus decreases further drastically. When we turn our attention to the vibrational intensity, as the $\mathrm{Q}^{3}, \mathrm{Q}^{2}$ and $\mathrm{Q}^{1}$ have non-bridging oxygens respectively, the vibrational intensity of glass increases further drastically.

\subsection{The Origin of the Excess Heat Capacity}

The relationship between the elastic modulus and the vibrational intensity is dual. The change of the $C_{p} T^{-3}{ }_{\max }$ is well explained by the change of the reallocated-and-isolated-microstructural units. And the hole model of liquid theory provides for resonant mechanism. Therefore, the origin of the excess heat capacity is the reallocated-main-network structure containing holes resonant with the reallocated-and-isolated-structural units.

\section{Conclusion}

The heat capacity $C_{p}$ of potassium germanate glass $\left(x \mathrm{~K}_{2} \mathrm{O} \cdot(100-x) \mathrm{GeO}_{2} ; x=0.0,10.1,19.0,28.2,39.0\right)$ was measured in the temperature range from 2 to $50 \mathrm{~K}$. It was found that the reduced excess heat capacity $C_{p} T^{-3}$ is caused by resonance of the reallocated main network structure containing holes with the reallocated isolated microstructural units. The relationship between the reduced excess heat capacity $C_{p} T^{-3}$ max and the elastic modulus is dual. The $C_{p} T^{-3}{ }_{\text {max }}$ indicates degree of freedom in the reallocated-and-isolated microstructure in glass. The hole model of liquid theory is useful to explain the mechanism of producing the resonant structure in the glass.

\section{Acknowledgements}

We are very grateful to T. Koyano and Y. Yamamura for the precise measurement of low-temperature heat capacity of potassium germanate glasses.

\section{References}

Anderson, P. W., Halperin, B. I., \& Varma, C. M. (1972). Anomalous Low-temperature Thermal Properties of Glasses and Spin Glasses. Philosophical Magazine, 25, 1-9. http://dx.doi.org/10.1080/14786437208229210

Buchenau, U., Galperin, Yu. M., Gurevich, V. L., Parshin, D. A., Ramos, M. A., \& Schober, H. R. (1992). Interaction of soft modes and sound waves in glasses. Physical Review B, 46, 2798-2808. http://dx.doi.org/10.1103/PhysRevB.46.2798

Chumakov, A. I., Monaco, G., Monaco, A., Crichton, W. A., Bosak, A., Rüffer, R., ... Piekarz, P. (2011). Equivalence of the Boson Peak in Glasses to the Transverse Acoustic van Hove Singularity in Crystals. Physical Review Letters, 106, 225501(5). http://dx.doi.org/10.1103/PhysRevLett.106.225501

Gil, L., Ramos, M. A., Bringer, A., \& Buchenau, U. (1993). Low-Temperature Specific Heat and Thermal Conductivity of Glasses. Physical Review Letters, 70(2), 182-185. http://dx.doi.org/10.1103/PhysRevLett.70.182 
Halliday, D., Resnick, R., \& Walker, J. (2001). Fundamentals of physics (6th ed.). John Wiley \& Sons.

Hannon, A. C., Martino, D. D., Santos, L. F., \& Almeida, R. M. (2007). A model for the Ge-O coordination in germanate glasses. Journal of Non-Crystalline Solids, 353(18-21), 1688-1694. http://dx.doi.org/10.1016/j.unoncrysol.2007.02.046

Henderson, G. S. (2007). The Germanate Anomaly: What do we know? Journal of Non-Crystalline Solids, 353(18-21), 1695-1704. http://dx.doi.org/10.1016/j.jnoncrysol.2007.02.037

Henderson, G. S., \& Fleet, M. E. (1991). The structure of glasses along the $\mathrm{Na}_{2} \mathrm{O} \cdot \mathrm{GeO}_{2}$ join. Journal of Non-Crystalline Solids, 134, 259-269. http://dx.doi.org/10.1016/0022-3093(91)90384-I

Kamitsos, E. I., Yiannopoulos, Y. D., Karakassides, M. A., Chryssikos, G. D., \& Jain, H. (1996). Raman and Infrared Structural Investigation of $\mathrm{xRb}_{2} \mathrm{O} \cdot(1-\mathrm{x}) \mathrm{GeO}_{2}$ Glasses. The Journal of Physical Chemistry, 100, 11755-11765. http://dx.doi.org/10.1021/jp960434+

Kiczenski, T. J., Ma, C., Hammarsten, E., Wilkerson, D., Affatigato, M., \& Feller, S. (2000). A study of selected physical properties of alkali germanate glasses over wide ranges of composition. Journal of Non-Crystalline Solids, 272, 57-66. http://dx.doi.org/10.1016/S0022-3093(00)00158-7

Kodama, M., Iizuka, K., Miyashita, M., Nagai, N., Clarida, W., Feller, S. A., \& Affatigato, M. (2003). Chemical composition analysis of alkali borate and alkali germanate glasses. European Journal of Glass Science and Technology A, 44, 50-58.

Kodama, M., Matsushita, T., \& Kojima, S. (1995). Velocity of Sound and Elastic Properties of $\mathrm{Li}_{2} \mathrm{O} \cdot \mathrm{B}_{2} \mathrm{O}_{3}$ Glasses. Japanese Journal of Applied Physics, 34, 2570-2574. http://dx.doi.org/10.1143/JJAP.34.2570

Mamiya, S., Matsuda, Y., Fukawa, Y., Kaneda, K., Kawashima, M., \& Kojima, S. (2010). Brillouin scattering study of binary potassium germanate glasses. Materials Science \& Engineering B, 173, 155-157. http://dx.doi.org/10.1016/j.mseb.2010.03.001

Mamiya, S., Matsuda, Y., Fukawa, Y., Kawashima, M., \& Kojima, S. (2009). Raman scattering study of binary potassium germanate glasses. European Journal of Glass Science and Technology B, 50, 321-324.

Matsuda, Y., Fukawa, Y., Ike, Y., Kodama, M., \& Kojima, S. (2008). Dynamic Specific Heat, Glass Transition, and Non-Debye Nature of Thermal Relation in Lithium Borate. Journal of Physical Society of Japan, 77, 084602(8). http://dx.doi.org/10.1143/JPSJ.77.084602

Phillips, W. A. (1972). Tunneling States in Amorphous Solids. Journal of Low Temperature Physics, 7(3-4), 351-360. http://dx.doi.org/10.10007/BF00660072

Richet, N. F. (2009). Heat capacity and low-frequency vibrational density of states. Inferences for the boson peak of silica and alkali silicate glasses. Physica B: Condensed Matter, 404(26), 3799-3806. http://dx.doi.org/10.1016/j.physb.2009.06.146

Richet, N. F., Rouxel, T., Kawaji, H., \& Nicolas, J. M. (2010). Boson Peak, Elastic Properties, and Rigidification Induced by the Substitution of Nitrogen for Oxygen in Oxynitride Glasses. Journal of the American Ceramic Society, 93(10), 3214-3222. http://dx.doi.org/10.1111/j.1551-2916.2010.03845.x

Richet, P., Ligny, D., \& Westrum Jr., E. F. (2003). Low-temperature heat capacity of $\mathrm{GeO}_{2}$ and $\mathrm{B}_{2} \mathrm{O}_{3}$ glasses: thermophysical and structural implications. Journal of Non-Crystalline Solids, 315(1-2), 20-30. http://dx.doi.org/10.1016/S0022-3093(02)0158-8

Soltay, L. G., \& Henderson, G. S. (2005). Structural differences between lithium silicate and lithium germanate glasses by Raman spectroscopy. Physical Chemistry of Glasses, 46, 381-384.

Temperley, H. N. V., \& Trevena, D. H. (1978). Liquids and their properties. Ellis Horwood Limited.

Wang, H. M., \& Henderson, G. S. (2004). Investigation of coordination number in silicate and germanate glasses using $\mathrm{O} \quad \mathrm{K}$-edge X-ray absorption. Chemical Geology, 213(1-3), 17-30. http://dx.doi.org/10.1016/j.chemgeo.2004.08.029

Yiannopoulos, Y. D., Kamitsos, E. I., \& Jain, H. (1997). Physics and Applications of Non-Crystalline Semiconductors in Optoelectronics.

Yiannopoulos, Y. D., Varsamis, C. P., \& Kamitsos, E. I. (2001). Density of alkali germanate glasses related to $\begin{array}{llllll}\text { structure. Journal of } & \text { Non-Crystalline } & \text { Solids, } & \text { 293, }\end{array}$ http://dx.doi.org/10.1016/S0022-3093(01)00677-9

Yiannopoulos, Y. D., Varsamis, C. P., \& Kamitsos, E. I. (2002). Medium range order in glass and the germanate 
anomaly effect. $\quad$ Chemical Physics $\quad$ Letters, $\quad 359(3-4), \quad 246-252$. http://dx.doi.org/10.1016/S0009-2614(02)00668-1

Yu, C. C., \& Freeman, J. J. (1987). Thermal conductivity and specific heat of glasses. Physical Review B, 36, 7620-7624. http://dx.doi.org/10.1103/PhysRevB.36.7620

Zeller, R. C., \& Pohl, R. O. (1971). Thermal Conductivity and Specific Heat of Noncrystalline Solids. Physical Review B, 4(6), 2029-2041. http://dx.doi.org/10.1103/PhysRevB.4.2029 